\title{
History of the Recrystallisation of Metals: A Summary of Ideas and Findings until the 1950s
}

\author{
Cesar Roberto de Farias Azevedo ${ }^{a}$ (1), Angelo Fernando Padilha ${ }^{a}$ (D) \\ a Universidade de São Paulo, Escola Politécnica, Departamento de Engenharia Metalúrgica e de \\ Materiais, Av. Professor Mello Moraes 2463, CEP 05508-030, São Paulo, SP, Brasil
}

Received: February 27, 2020; Revised: April 19, 2020; Accepted: April 27, 2020

\begin{abstract}
The paper reviews the events that led to the understanding of the recrystallisation of metals throughout history, covering the timeline from $3500 \mathrm{BC}$ until the 1950s and dealing mainly with the misconceptions related to the "recrystallisation" and "amorphisation". This history begins with the thermomechanical processing of native metals in pre-Columbian America (3,000 BC), and the production of brass coins in Rome (100 BC). The analysis of the fracture surfaces of metals, commonly used between the $16^{\text {th }}$ and $18^{\text {th }}$ centuries in Europe for the quality control of metallic products, is briefly discussed. The observation of crystalline and fibrous fractures lead to the common misconception of the $19^{\text {th }}$ century that "recrystallisation" takes place during the heating of "amorphous" cold-worked metals. The use of reflecting optical microscopy in the late $19^{\text {th }}$ century indicated, however, that the plastic deformation only promotes a morphological change in the microstructure of the metals without any "amorphisation". In the early $20^{\text {th }}$ century, the plastic deformation of metals by crystal plane slipping and twinning was well documented by metallographic observation during tensile testing. Nevertheless, in 1915, Prof. Rosenhain advocated that the "crystal" inside the slip bands of a plastically deformed metal was "amorphous" and responsible for the work hardening. The discovery of the X-ray diffraction technique, in 1913, allowed to resolve the ongoing dispute of the "amorphisation" of metals during plastic deformation. Between the 1920s and 1950s, X-ray diffraction was practically the only means of studying the internal structure of metals to explain the nature of their plasticity, confirming many aspects of the dislocation theory. This technique was crucially important to understand the atomic crystal structure of metals in the annealed and cold-work states. Our history finishes in the 1950s when the transmission electron microscopy finally revealed the first images of dislocation in metals. Up to that date, most of the understanding of the dislocations' distribution and organisation in cold-work and annealed states had already been derived from X-ray diffractograms, which gave birth to the modern physical metallurgy.
\end{abstract}

Keywords: Recrystallisation of metals, history, fractography, optical microscopy, x-ray diffraction.

\section{Introduction}

The production of metallic parts is impressive by its quantity ( $\sim 1$ billion tons/year) and its vast range of processes and products. During the industrial revolution, there were about a hundred materials, and today the number exceeds one hundred thousand, the vast majority are metallic materials. Approximately $90 \%$ of the production of these metals and alloys are thermomechanically produced and the understanding of all the phenomena involved during the work hardening, recovery, recrystallisation and grain growth is fundamental to control the properties of the metallic products. Metallurgy did not begin with casting but with the application of plastic deformation to shape to the native metals into weapons and tools as early as 7,500 BC in the region of Anatolia. Wrought objects in copper, gold and silver were produced in the area close to the Persian Gulf several millennia ago ${ }^{1-4}$. The use of native copper in the American continent started between 3,000 and 1,500 $\mathrm{BC}$ with prehistoric cultures in the Lake Superior, North America. Investigation of twenty native copper artefacts ${ }^{5}$ from the collections of the Chicago Field Museum and Peabody Museum at Harvard University indicated that an axe head (see Figure 1a) was manufactured by annealing the native copper at temperatures above $600^{\circ} \mathrm{C}$ followed by extensive cold-hammering. A copper spearhead (see Figure 1b) was produced using a similar annealing-step to avoid the cracking of the artefact during further cold working ${ }^{5}$. According to the authors ${ }^{5}$, a standard practice for shaping native copper objects was to hammer and anneal the metal repeatedly until the final shape was obtained. After the final annealing, the metallic artefact could be cold-worked or left in an annealed condition. Native gold adornments produced by cold hammering dated from 2,000 $\mathrm{BC}$ were found in the Lake Titicaca region, Peru ${ }^{6,7}$. According to the authors ${ }^{6}$ :

"Each of the ornaments shows distinctive hammer marks, suggesting that the raw native gold was first flattened with a stone hammer and then carefully bent and/or hammered around a hard cylindrical object to create the tubular shape. Despite the hammering, the metal maintained its ductility through this process". 
Thermomechanical processing of native copper was also used to manufacture an anthropomorphic mortuary mask dated 1,000 BC and found in the Argentinian Andes. The microstructure of a sample of this mask indicated that the native copper was subjected to either a process of heating and hammering or hammering and annealing ${ }^{8}$. The Romans learned and mastered some technical aspects of the thermomechanical production of various metallic objects ${ }^{1,8}$. The use of gold, silver (since $400 \mathrm{BC}$ ), copper, bronze and brass alloys to manufacture the Roman coins, for instance, is one of the pioneering mass production of metallic artefacts in history. The main minting processes were casting and plastic deformation; the latter could use hot or cold striking ${ }^{9-11}$. The metallographic analysis of two types of brass coins used by the Romans (Dupondius and AE) indicate the use of hot striking at temperatures above $800^{\circ} \mathrm{C}$, see Figures $2 \mathrm{a}$ and $2 \mathrm{~b}^{10,11}$. According to Calliari et al. ${ }^{12}$, the Roman coinage process of $\mathrm{Cu}$-base alloys between 100 and $300 \mathrm{AD}$ could be divided into four steps: the production of alloys and casting; the blank manufacture; the hammering and annealing to produce the coin geometry; and the coin embossing by die striking. During the minting process, mechanical work and annealing were performed using many parameters, such as alloy chemical composition, as-cast microstructure, working temperature and time, amount of strain and strain rate.
All these parameters control the recrystallisation and grain growth processes, which control the mechanical properties of the coins ${ }^{12,13}$.

Some of the early iron objects, such as the iron dagger blade from the sarcophagus of Tutankhamun (14,000 BC), were produced by the careful cold hammering of meteoritic iron (Fe-Ni alloys) ${ }^{14}$. The Iron Age began after 2,000 BC, when iron replaced bronze in the production of "stronger" tools and weapons, is a break-through in the history of technology ${ }^{15,16}$. At the beginning of the Christian era, seven metals and some metallic alloys were already widely used ${ }^{17}$. Metallographic ${ }^{18}$ examination of Roman ferrous armours from Britain, dating between 100 and $300 \mathrm{AC}$, indicated a deep understanding of the use of iron and steel associated with their hot or cold-working processing for the production of high-quality thin plates, see Figures $3 \mathrm{a}$ and $3 \mathrm{~b}$. This knowledge was not surpassed in Europe until the late fifteenth centuries ${ }^{18}$. The available empirical knowledge on work hardening and recrystallisation of metals and alloys were summarised by Biringuccio ${ }^{19}$ published in 1540:

"Every work of gold and silver, as well as copper, may be worked either hot or cold, only you must be careful to anneal the thing at every hammering or when it needs it'.
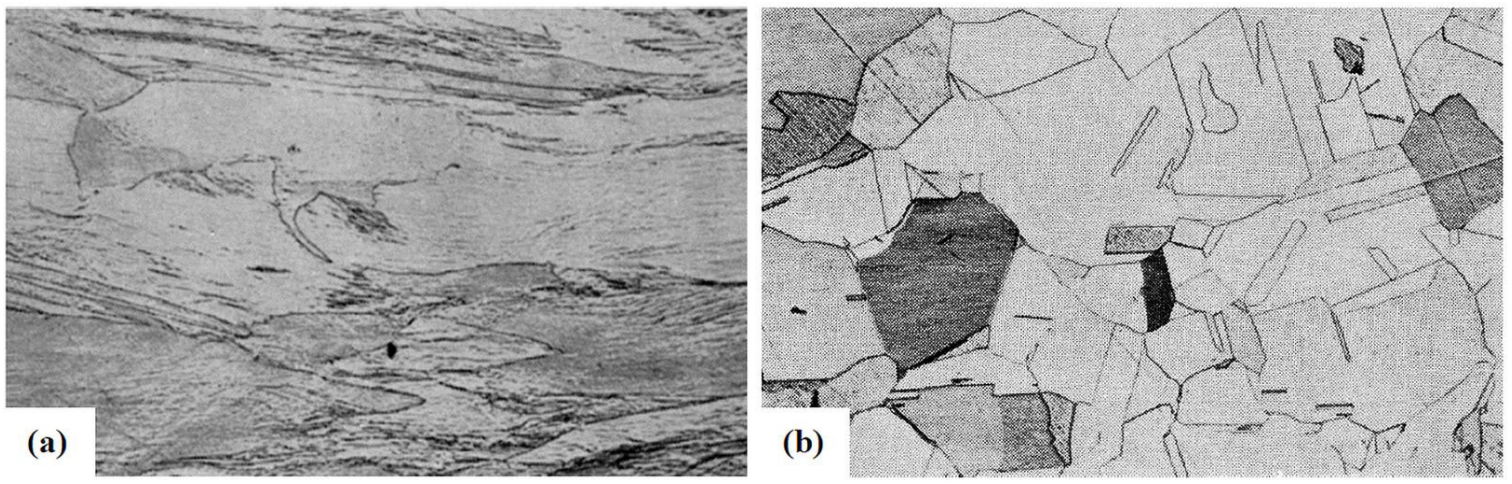

Figure 1 - Microstructural characterisation of prehistoric wrought native copper artefacts found in the Lake District, North America (1,500 to 100 BC). (a) Axe head found in Sault Ste. Marie, Canada. Cold-worked condition, hardness of 116 VHN, featuring a 10 to 1 elongation ratio due to plastic deformation; (b) Spearhead found in Waupaca, Wisconsin, USA. Fully recrystallised microstructure, hardness of $59 \mathrm{VHN}$, and twinned equiaxed grains. Note the absence of non-metallic inclusions in both artefacts. Optical microscopy, potassium dichromate and ferric chloride etching, magnification of $50 \mathrm{x}^{5}$.
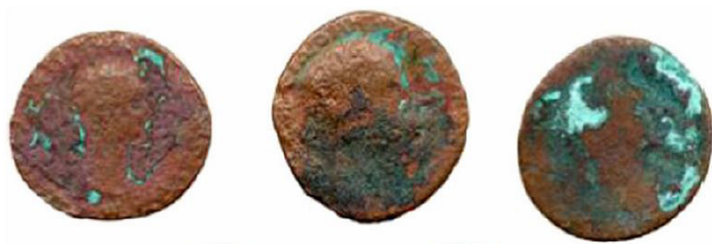

(a)
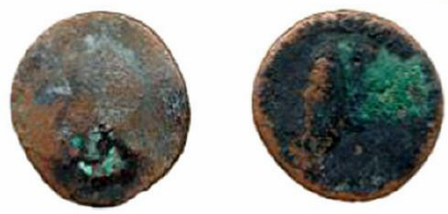

Figure 2 - Thermomechanical processing in Rome. (a) Dupondii Cu-Zn brass coins with partial patina; (b) Microstructure of a Dupondii brass coin, showing equiaxed $\alpha$-grains and annealing twins (recrystallised microstructure), longitudinal cross-section, optical microscopy ${ }^{10}$. 

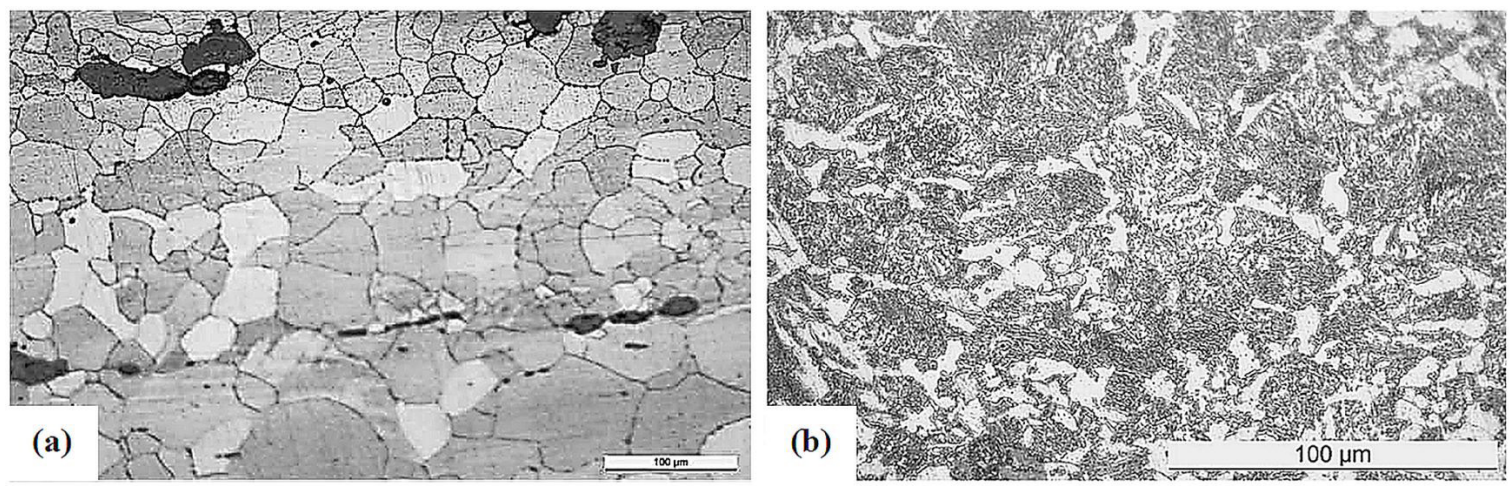

Figure 3 - Roman ferrous armour from Northern Britain, 100 AC to 300 AC. (a) Microstructure of Vindolanda Lorica wrought iron armour, featuring equiaxed recrystallised ferritic grains, elongated slag inclusions and grain boundaries precipitates. The grains near the surface are more refined than the centre; (b) Detail of the microstructure of Carlisle Scale Arm steel armour, featuring ferritic grains and spherodised pearlite, indicating the occurrence of an annealing heat-treatment after the forging ${ }^{18}$.
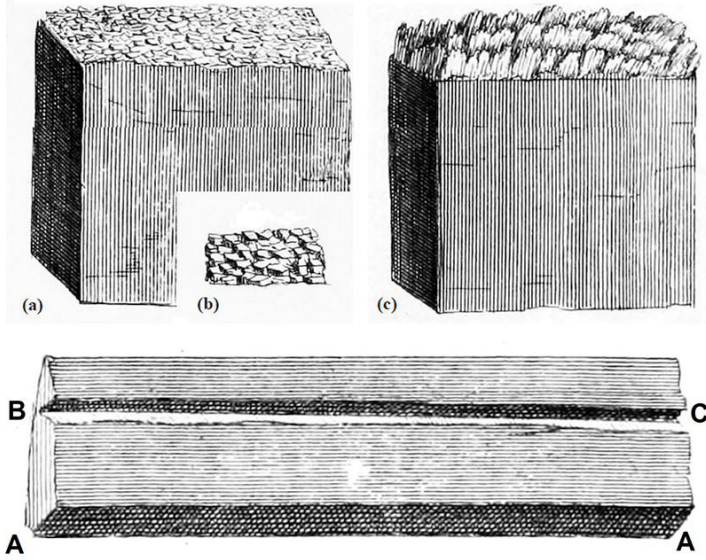

(d)

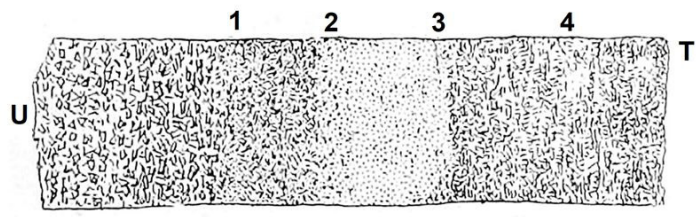

(e)

Figure 4- Sketches from Réaumur, depicting the fracture appearance of iron bars ( $a$ and b) and steel bars (c). (a) Crystalline or brittle fracture of a forged bar of a low-quality iron; (b) Fibrous or ductile fracture of a forged bar of a high-quality iron; (c) Fracture of a steel bar quenched after heterogeneous heating. (d) The heating of the steel bar fracture standard took place from the top end (see U), while the lower end (see T) remained cold. Quenching and fracture followed the heating. (e) The fracture surface revealed differences in the grain size (see 1-3) along the bar, where the coarser grains resulted from the exposure to higher temperatures, while region 4 was not hot enough to respond to the quenching. Adapted from ${ }^{21}$.

\section{Main Developments Between the XVI and XIX Centuries Concerning the Deformed and Annealed States}

From the sixteenth to late-eighteenth centuries, the macroscopic and microscopic appearances of the fracture surfaces of metallic test-pieces were used to control the processes of casting, forging and iron-to-steel conversion ${ }^{19-25}$.
Additionally, the fractography was used to assess the quality of metallic products ${ }^{19-25}$. Brittle fractures were composed by a group of smaller reflective grains exhibiting a crystalline appearance, which was an indication of the poor quality of the metallic product. Ductile fractures feature a fibrous appearance, resembling the fracture of wood, indicating the outstanding quality of the metal in terms of toughness ${ }^{19-25}$. In 1722, the remarkable French scientist, knight and seigneur of Réaumur, already assumed that the internal structure of the iron and steel was that of its fracture, so a forged iron was composed of smaller grains, fibres or a mixture of both, depending on the topography of its fracture surface (see Figures 4a to 4c) ${ }^{21}$. Réaumur ${ }^{21}$, for instance, investigated the fracture surface of notched steel bars (see Figure 4d) submitted to a sharp temperature gradient (one end of the bar was heated melting-hot), which was followed by quenching and the application of gentle blows to fracture the bars (see Figure 4e). Réaumur noticed after observing the fractures of these Jominy-like testing samples that:

"In the fractures obtained by one of the methods just described, one glance reveals the whole range of different grain sizes a steel can be given by all the different degrees to which it can be heated. We are now able to compare the finest grain of one steel with the finest grain of another. Artisans who wish to know what they are doing should have a stock of such fractures of every grade of steel in the Kingdom. These would serve them as standards to measure the degree of fineness of the steels which are offered them for sale."

In the $19^{\text {th }}$ century, mechanical testing and fractography of metallic samples became more popular, and the investigation of railway accidents indicated that the fracture surface of the wrought iron axles changed from fibrous (fracture appearance after bending testing of the material before service) to crystalline during service (fracture aspect of the failed shaft exposed to cyclic loading). These observations suggested that cyclic loading crystallised the amorphous wrought iron ${ }^{22,25,26}$. Kirkaldy ${ }^{26,27}$ refused the idea that vibration caused the crystallisation of the wrought iron during service and he showed that the appearance of the fracture surface of wrought iron and steel depended on the loading mode so that the same piece of wrought iron could 
produce different fracture surfaces under different testing conditions. Stephenson ${ }^{26}$ examined iron samples featuring fibrous fracture under a microscope and noticed that at higher magnifications, the fibres were a crystalline mass; while Brune ${ }^{26}$ pointed that heating could also produce variations in the appearance of the fracture of wrought iron:

"Iron in a cold state shows a more crystalline fracture than the same iron warmed a little".

In 1868 , Chernoff ${ }^{28}$, also known as Tschernoff ${ }^{29}$, showed that heating the steel above a critical temperature would cause the amorphisation of its crystalline structure, while the cooling rate from this temperature would define its final structure (either as amorphous, or fined to large-grained crystalline). According to the author ${ }^{28,29}$, any steel parts, such as wagon axles and engine shafts, which lost their original strength and tenacity during service due to the "crystallisation process", could have their mechanical properties restored by heating the parts above a critical temperature, followed by controlled cooling to either restore the amorphous structure or produce a finely grained crystalline structure. The Russian metallurgist finally stated the relationship between the structure of the steel obtained by heat-treatment and its mechanical properties:

"It is better to obtain steel of a finely crystalline structure because numerous experiments have demonstrated that the greater the preponderance of the crystalline formation, and the larger and more regular the crystals in a given piece of steel, the less resistance does it offer to fracture, the less tenacity does it possess."

Concerning the debate of the fracture type (fibrous or crystalline) versus the as-wrought structure of the iron (amorphous or crystalline), Percy ${ }^{30}$ unmistakably stated in 1864 that:

"By the operation of rolling, the crystals are drawn out in one direction, into wires, as it were; and the resulting bar, therefore, will be composed of parallel and continuous bundles of such wires. But the crystalline structure is not thereby obliterated, the crystals having been merely elongated".

Other scientists investigated the changes in the mechanical properties of metals caused by solid-state heating, such as Savart $^{31}$, Noguès ${ }^{32}$ and Kalischer ${ }^{33}$. Felix Savart was a French physician who contributed to various areas of knowledge, notably in electricity and acoustics. Savart ${ }^{31}$ was able to associate, as early as 1829 , the acoustic anisotropy of cast ingots of various metals featuring coarse grains. After plastic deformation and annealing of these ingots, the acoustic anisotropy decreased significantly due to a structural change occurred during the annealing of a cold-worked metal. Alphonse Noguès, a French mining engineer who taught at the Faculty of Sciences in Santiago, Chile, observed in 1858 , the presence of coarse granulation in the platinum wires exposed to high temperatures ${ }^{32}$. The crystallisation and grain growth of the platinum wires were attributed to a change on its "molecular state". In 1881, Kalischer" ${ }^{33}$ investigated the effect of the heat treatment of zinc sheets using bend, fracture and sonority tests. He etched the surface of the zinc samples with a solution of copper sulphate and concluded that the plastic deformation destroyed the "crystallinity of the zinc" and that later annealing at particular combinations temperature and time restored its crystallinity, so these heat- treatments were thought to recrystallise the zinc. According to Kalischer ${ }^{33}$ :

"The development can be understood in such a way that the crystalline structure of the zinc, obtained during its solidification, is lost during rolling, but when reheated to a given temperature, higher than the one obtained by rolling, it recovers its crystalline structure".

The term "Krystallisation" was born in 1881 to explain "the reversible solid-state transition" between "the amorphous and crystalline states" due to plastic deformation and heating ${ }^{33}$. In 1882, Kalischer ${ }^{34}$ extended his studies to several metals and alloys. Most of the investigated samples were in the form of sheets, but some in the form of bars and wires. He was evaluating which metals had a greater tendency towards amorphisation during cold working, and his conclusions were drawn by the naked-eye examination of the specimens after plastic deformation, annealing and fractography. He established, for instance, that metals such as cadmium, silver and gold became amorphous because of the rolling, and crystallise again on annealing. Kalischer concluded that the stable state for most metals was the "crystalline state":

"This state can be destroyed by mechanical forces with varying ease, though sometimes perhaps not at all. In many cases, the crystalline structure can be re-established by heating".

The concepts of the solid-state amorphisation, crystallisation and recrystallisation of metals were extensively studied, discussed and misunderstood during the 19th century, mainly due to the misleading morphological aspects of the fracture surfaces of metals. Few visionaries were aware that the appearance of the fracture surface of metals and alloys also depended on the mode of mechanical loading, and that the plastic deformation of metals did not promote its amorphisation.

\section{Early Investigation of The As-deformed and Recrystallised Microstructures Using Optical Microscopy}

The use of reflective optical microscopy to observe the microstructure of steels started in Sheffield in the year of 1864 with the original work of the geologist Henry Sorby, who was using samples of steel as artificial-meteorites to develop a methodology to study the structure of real meteorites, probably stimulated by the work of Widmanstätten and Schreibers, who had been investigating the structure of meteorites in Vienna since $1808^{22}$. The understanding of the relationship between the microstructure, the chemical composition, the processing conditions and the mechanical properties of steels ${ }^{35-40}$ was one of the crucial scientific facts in the late XIX century, leading to the birth of physical metallurgy and materials science in the XX century. In 1887, Sorby ${ }^{36,37}$ published a review of his early works on the metallography of steels, demonstrating that the effect of the cold work was to elongate the grains of the polycrystalline microstructure, as previously stated by Percy ${ }^{30}$ in 1864 . Sorby also indicated that the deformed grains were unstable and that "recrystallisation" during annealing allowed the deformed microstructure to return to a stable condition ${ }^{36,37}$. 
"When such a (iron) bar is hammered cold the crystals are compressed, broken up, distorted and elongated in the line of the bar. When kept some time at the red heat, these distorted crystals recover their ultimate regular structure by recrystallising, the tendency being to often grow in a line perpendicular to the direction in which they were previously elongated".

In 1898, the British metallurgist John Edward Stead (1851-1923) $)^{41,42}$ investigated the granulation of iron and steels after plastic deformation followed by heat-treatments at low temperatures (below $750^{\circ} \mathrm{C}$ ) for varying times. Samples of plastically-deformed-and-decarburised soft steel were heated either for one hour at $600^{\circ} \mathrm{C}$ or two hours at $650^{\circ} \mathrm{C}$, and the metallographic examination indicated that the lenticular microstructure, featuring grains with a length of $125 \mu \mathrm{m}$ and width of $25 \mu \mathrm{m}$, was fully restored to an equiaxed microstructure with a grain size of approximately $25 \mu \mathrm{m}^{41}$. According to Stead, when a soft iron was plastically deformed, the original equiaxed polygonal grains of the microstructure assumed a lenticular appearance and the toughness and hardness of the metal was increased:

"The microscope reveals no other change in the structure than a change in the form of the grains. It is known that by heating such a drawn-out and hardened material to a dull red heat its original ductility is restored. The question naturally presenting itself was whether or not such physical change is accompanied by a structural alteration".

Stead $^{41}$ observed that the microstructure of plastically deformed steel bars did not change after quick heating at $700^{\circ} \mathrm{C}$, but when heated at $700^{\circ} \mathrm{C}$ for 3 hours, the microstructure changed to large equiaxed grains. He concluded that heating at $700^{\circ} \mathrm{C}$ caused a reorganisation in the crystalline structure of steel due to the action of crystalline forces. On describing the forged microstructure of a decarburised steel after heating at $700^{\circ} \mathrm{C}$ for 3 hours, Stead ${ }^{41}$ noticed there were isolated large grains surround by smaller grains, indicating that the reorganisation and the crystallisation started from isolated centres of the cold-worked microstructure (see Figure 5). In 2004, Humphreys and Hatherly ${ }^{43}$ observed that the grain growth by the grain rotation and coalescence mechanism had been proposed by Stead ${ }^{42}$ in 1898 . Stead ${ }^{42}$ heated fine-grained pure iron between 600 and $750{ }^{\circ} \mathrm{C}$ and suggested:

"... at the temperature of between 600 and 750 degrees centigrade the axes at many different angles of several contiguous grains alter their position until they become of the same angle in all, with a coincident disappearance of the granular junctions, the result being a larger grain containing the same mass as the sum of all the masses of the smaller grains added together".

In 1899 and 1900, Ewing and Rosenhain ${ }^{44-46}$ observed the polished and etched surfaces of the metallic specimens during tensile testing, and they concluded that the metals deform plastically by the slip of their crystalline planes (observation of slip lines); and the metals do not lose their crystallinity during plastic deformation. They proposed that when metallic samples were deformed beyond their yield strength, the plastic deformation occurred through "the sliding of the elementary portions of each crystalline grain":
"As soon as plastic deformation begins the faces of the grains show fine black lines, and as the strain increases these lines increase in number; they are more or less straight and parallel in each grain, but they are differently directed in different grains. The first lines to appear are those approximately transverse to the pull, but as the strain increases systems of inclined lines appear on the other grains. With further straining, some of the grains begin to show more than one system of such lines, and eventually, two, three, and even four systems of intersecting lines on a single grain may be seen".

The observed slip-bands on the surface of the test pieces due to slip of individual planes during the plastic deformation of metals is shown in Figures 6 and Figures 7a to 7c. Some

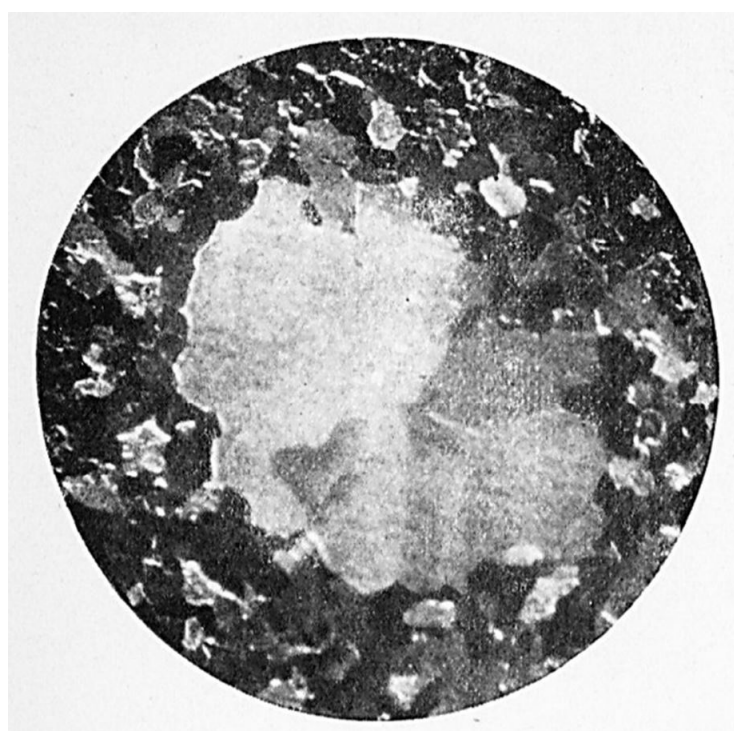

Figure 5-Microstructural characterisation of a plastically deformed iron bar $(\mathrm{C}=0.01 \%)$ after heat treatment at $700^{\circ} \mathrm{C}$ for 3 hours, showing heterogeneous distribution of ferrite grain size, where the central portion features larger grains. Optical microscope, magnification of $50 x$, etching in $\mathrm{HNO}_{3}{ }^{41}$.

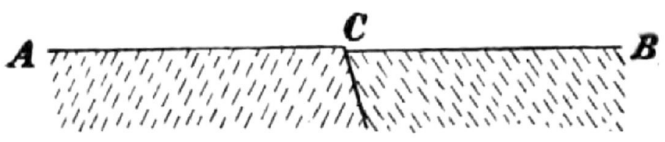

(a) Before straining.

(b)

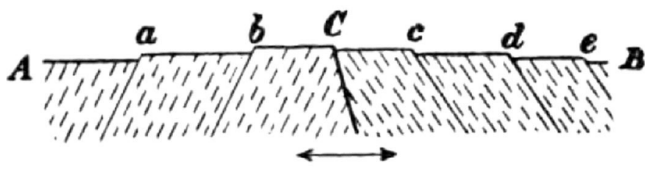

After straining

Figure 6 - Slip-bands (a) Representation of a section of a region of the tensile test-pice, showing two contiguous surface grains, where cleavage or gliding planes are indicated by dotted lines, $\mathrm{AB}$ is the polished surface, $\mathrm{C}$ is the junction between the two grains; (b) Formation of steps (slip-bands) due to the slip of preferential planes. The points $\mathrm{a}, \mathrm{b}, \mathrm{c}, \mathrm{d}$ and e show the finite amounts of plane slip ${ }^{44}$. 
metals showed straight slip-bands (such as $\mathrm{Pb}, \mathrm{Au}$ ), while in others (such as Ag) the slip-bands were wavy. They observed twinning during the plastic deformation of $\mathrm{Cu}, \mathrm{Au}, \mathrm{Ag}, \mathrm{Pb}, \mathrm{Cd}$, $\mathrm{Sn}, \mathrm{Zn}$ and $\mathrm{Ni}$ (see Figure $7 \mathrm{c}$ ) and concluded that there were two mechanisms for the plastic deformation: slipping (translational movements of the lattice elements with preservation of the orientation) and twinning (rotational movements through an angle, which is the same for "each molecule"). They also observed that the plastically deformed metals featured different aspects of the slip-bands when compared to the annealed ones.

Ewing and Rosenhain ${ }^{45}$ proved that the higher the annealing temperature, the more rapid was the recrystallisation. They proposed the "theory of corresponding temperatures", whose central idea was that the properties and behaviour of metals were a function of their distance from their melting points (homologous temperature). The recrystallisation rate also depended on the number of impurities and the severity of the strain, and they suggested that the presence of contaminants promoted the formation of an intergranular eutectic, whose presence controlled the recrystallisation phenomena in metals. They concluded that in perfectly pure metal, the recrystallisation after severe strain should not occur ${ }^{45}$. Rosenhain ${ }^{46}$ wrote that when a cold-worked piece of metal is heated, the first remarkable effect is that of mechanical softening, which precedes any noticeable impact on the microstructure. He explained that the process of annealing in most metals occurs in two stages and that the mechanical softening did not alter the plastically deformed microstructure. This primary stage was followed by the gradual recrystallisation and formation of new crystals of equiaxed shape.

Surprisingly, in 1915 Rosenhain ${ }^{46}$ started advocating that the metal inside the slip bands of a plastically deformed metal was amorphous, accounting for the hardening of the metal during the cold working, and contradicting his previous ideas about the crystallinity of the cold-worked state. His proposal of a hardening mechanism caused by the formation of a network of amorphous layers acting "as a stiffening skeleton for the whole crystal and thus offer additional resistance to the commencement of fresh slip" is visually analogous to the concept of dislocation tangles and cells:

"The essence of the whole conception implies that the plasticity in metals is a property bound up with the crystalline structure. As amorphous layers are formed, the capacity of the crystals to yield by slip is diminished, and ultimately, when a certain not very large proportion of the metal has been converted into the amorphous condition, the metal has been rendered incapable of further plastic deformation - it has been rendered hard and brittle. As this stage is reached when the metal still consists largely of portions of crystals embedded in amorphous layers, it is obviously impossible to convert the whole of the metal into the amorphous condition, because the straining process whereby this conversion can be brought about is rendered impossible by the skeleton of hard amorphous matter already present".

In 1920, Prof. Carpenter (Royal School of Mines, London) and Miss C. F. Elam ${ }^{47}$ proposed the stored energy during the cold-work of metals provided the driving force for the recrystallisation, while the grain boundary energy controlled the grain growth. They also noted that the terms "recrystallisation" and "crystal growth" were previously used for the most part, indiscriminately and interchangeably, usually resulting in misunderstanding during the discussions ${ }^{47,48}$. Part of their investigation dealt with the effects of plastic deformation on the recrystallisation. They concluded that the presence of amorphous layers could not explain the work-hardening in metals, as proposed by Rosenhain ${ }^{46}$, and that crystal growth always took place by gradual boundary migration, and not by coalescence, as suggested by Stead ${ }^{42}$. They concluded that the recrystallisation was induced by plastic deformation, and the size of the recrystallised crystals was dependent on the extent of the plastic deformation. They also reasoned that there is an upper limit to the crystal growth as a single crystal had not been created by prolonged annealing; and that the growth of crystals during annealing tool place after the mechanical softening. They finally concluded that:

"... until much fuller knowledge of the structure and properties of crystals has been obtained, the true explanation of the effects of work upon metals will not be forthcoming".

\section{Understanding The Internal Structure of the Plastically Deformed and Annealed States Using X-ray Diffraction}

By late XIX century, the crystallography was already a well-established field of study ${ }^{49,50}$ and the metals were classified as "crystalline" materials, containing habit and
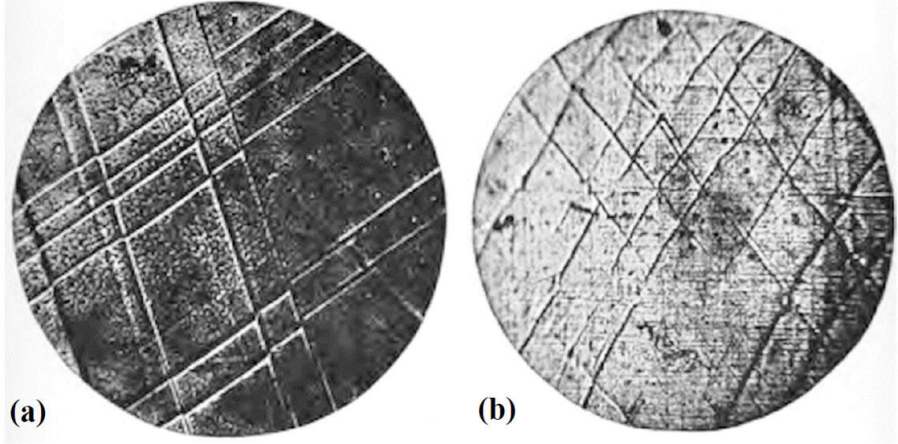

(c)

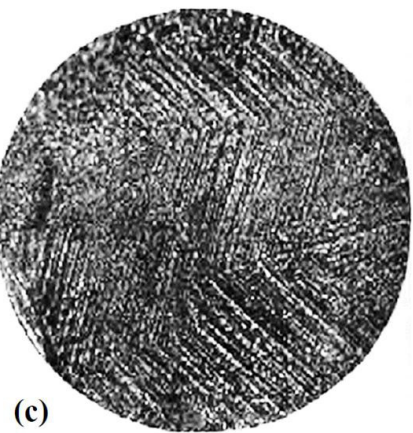

Figure 7 - Morphology of the slip-bands on the surfaces of tensile test-pieces. (a) Lead, straight primary and secondary slip-bands; (b) Silver, curvy primary and secondary slip-bands; (c) Copper, mechanical twinning ${ }^{44}$. 
cleavage planes, but their real internal crystal structure was yet not known or proved. The discovery of the X-ray diffraction took place in 1912, when Laue, Friedrich and Knipping emitted a white X-ray beam against single crystals of copper sulphate pentahydrate and zinc-sulphide $(\mathrm{ZnS})$ and observed discrete diffraction spots in the diffraction chamber $^{51-53}$, indicating the atomic arrangement in crystals ${ }^{51-53}$. Lawrence Bragg suggested that these spots were due to the diffraction of the X-ray waves on the various families of the lattice planes of the crystal ${ }^{54,55}$, and he used the position of these diffraction spots to determine the crystal structure of $\mathrm{ZnS}$, face-centred cubic lattice ${ }^{54-57}$. The use of X-ray diffraction opened the possibility of determining the crystal structures of metals and alloys and revolutionised the new field of physical metallurgy ${ }^{56-59}$.

The first observations of Laue diffraction spots in metals were reported by Owen and Blake ${ }^{60}$, Moseley ${ }^{61-63}$ and Lawrence Bragg ${ }^{57,64}$. X-ray diffraction showed that the constituting elements of metallic crystals were atoms and not molecules. The technique was employed to investigate the crystal structure of phases and phase diagrams and the defects of the crystal lattices ${ }^{64-101}$.

Mark et al. ${ }^{73-75}$ studied the plastic deformation of zinc single-crystals, hexagonal close-packed crystal structure, and identified the slip planes (basal and prismatic planes) and slip directions (close-packed directions) acting during the plastic deformation of zinc single-crystals. Additionally, they observed the rotation of the crystal lattice during the plastic deformation. The crystalline structure of the metal was conserved during the cold working, but the diffraction diagrams of both single-crystalline and polycrystalline metals in the plastically deformed state picture modifications in the diffraction patterns, indicating that the plastic deformation somehow affected the lattice structure. Diffraction diagrams of metals and alloy obtained with monochromatic X-rays showed the differences between the annealed and deformed state were related to the length and the position, width and intensity of the diffraction spots ${ }^{76}$.

The first observations of the influence of cold-rolling and annealing on the X-ray diffraction pattern of single crystals indicated that the plastic deformation did not change the structure of the metal from a crystalline into amorphous, as stated by Rosenhain ${ }^{46}$. However, the plastic deformation of a metallic single-crystal introduced few "anomalies" in the Laue diagrams, such as the presence of halos and star-shaped spots (asterisms), see Figures 8a and 8b. The asterisms, for instance, indicated that regions of different orientations (crystallites) were present in the plastically deformed single crystals (local curvatures of the lattice) and these regions were separated by walls of dislocations ${ }^{53,59,79,82,90-95,100}$. An exception was observed for cadmium single crystals, tensile-tested at room temperature with their basal plane located near parallel the maximum shear stress and the X-ray Laue photographs did show very faint asterisms even for strains of $100 \%$ (easy-glide), see Figure $8 \mathrm{c}$. The extended Cd single crystals were then bent around cylindrical mandrels with radius varying from 5 to $1 \mathrm{~mm}$ and, in this new configuration, the basal plane of the Cd crystals are almost parallel to the bending axis $\left(45^{\circ}\right.$ of the maximum shear stresses). Comparatively stronger asterisms were observed after bending around a 3.5 diameter mandrel (see Figure 8d), which were transformed into various fragmented spots by poligonisation during the recovery at $290^{\circ} \mathrm{C}$ for 24 hours (see Figure 8e). Recrystallisation was only observed for the most severely bent Cd sample (around a 1.75 diameter mandrel) after the annealing at $290^{\circ} \mathrm{C}$ for 24 hours; see Figure $8 \mathrm{f}^{90}$.

In polycrystalline metals, the plastic deformation, recovery and recrystallisation also changed the Debye-Scherrer
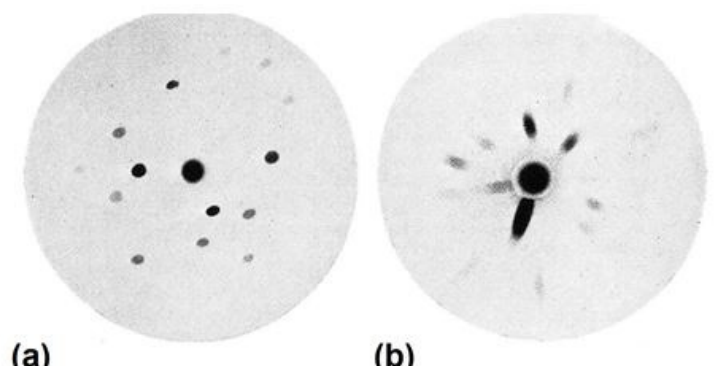

(a)

(b)
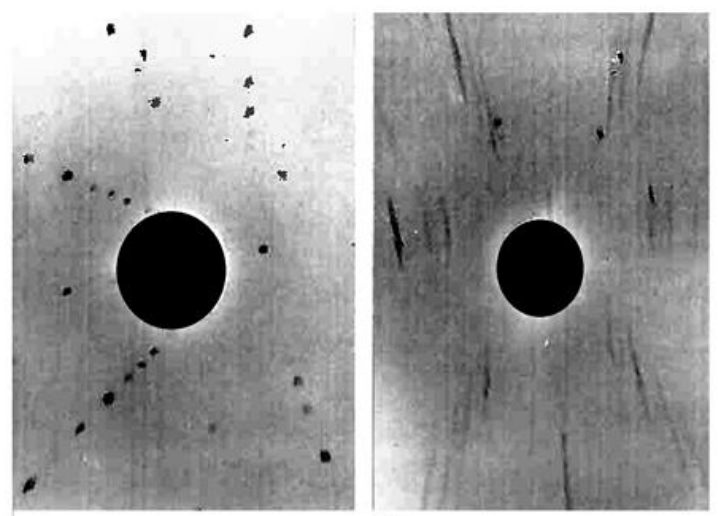

(c)

(d)
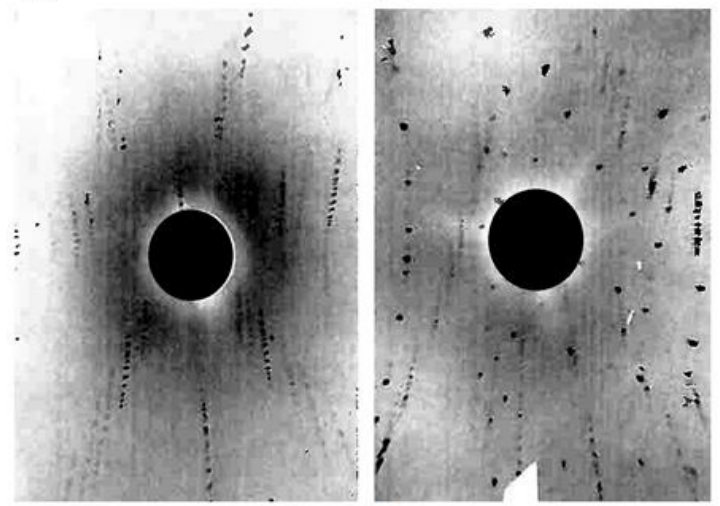

(e)

(f)

Figure 8 - Aluminum and cadmium single crystals, Laue X-ray diffraction figures. (a) Undeformed Al; (b) Plastically deformed Al ( $20 \%$ extension and $30 \%$ rolling), showing elongated spots (asterisms), which appear due to the rotation of the crystal $^{76}$; (c) to (e) Cd single crystals, Laue diffraction figures ${ }^{90}$ : (c) As-deformed Cd (100\%), showing faint asterisms; (d) As-bent $\mathrm{Cd}$, showing prominent asterisms; (e) Bent Cd after annealing at $290^{\circ} \mathrm{C}$ for $24 \mathrm{~h}$. The recovered state is indicated by the presence of crystallites (separated reflection spots); (f) Severely bent Cd after annealing at $290^{\circ} \mathrm{C}$ for $24 \mathrm{~h}$ (sharp Laue spots). The recrystallised state is indicated by the presence of larger grains (sharp and separated reflection spots) ${ }^{90}$. 
photograms. Becker ${ }^{78}$ in 1927 showed the powder diffraction diagrams for fine-grained polycrystalline tungsten wires after cold drawing, partial-annealing and recrystallisation (coarse grain), see Figures $9 \mathrm{a}$ to $9 \mathrm{c}$. He indicated that after the plastic deformation, the two $K \alpha_{1}$ and $K \alpha_{2}$ lines of the 400 plane were merged into a single peak (peak-broadening), while after some annealing the original doublet was observed again. After the recrystallisation, however, the continuous diffraction lines changed into broken lines, corresponding to the formation of large individual crystallites. Additionally, the X-ray patterns showed the presence of arcs with localised intensity maxima, indicating the preferred orientation of the crystallographic planes and crystallographic directions after the plastic deformation (see Figure 9a). X-ray diffraction of cold-worked metals also showed that during the plastic deformation, a single grain disintegrated into a mosaic of small fragments with various crystallographic orientations and the size of the crystallites could be deduced from the broadening of suitable diffraction lines ${ }^{82-87}$. According to $\mathrm{Bragg}^{88}$, the first effect of the plastic deformation of a perfect crystal is to produce these crystallites (see Figure 10), whose sizes ranged from $1 \mu \mathrm{m}$ for $\mathrm{Al}$ to $0.1 \mu \mathrm{m}$ for $\mathrm{Cu}^{86,87}$.

One of the technical challenges of the X-ray diffraction technique between the 1930s and 1950s was to separate and quantify the effects of the elastic deformation of the lattice,

(a)

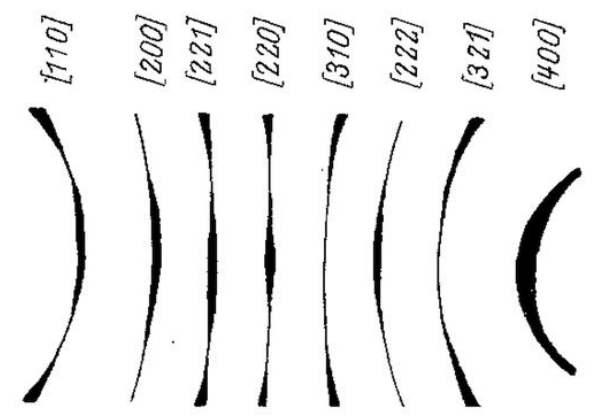

(b)
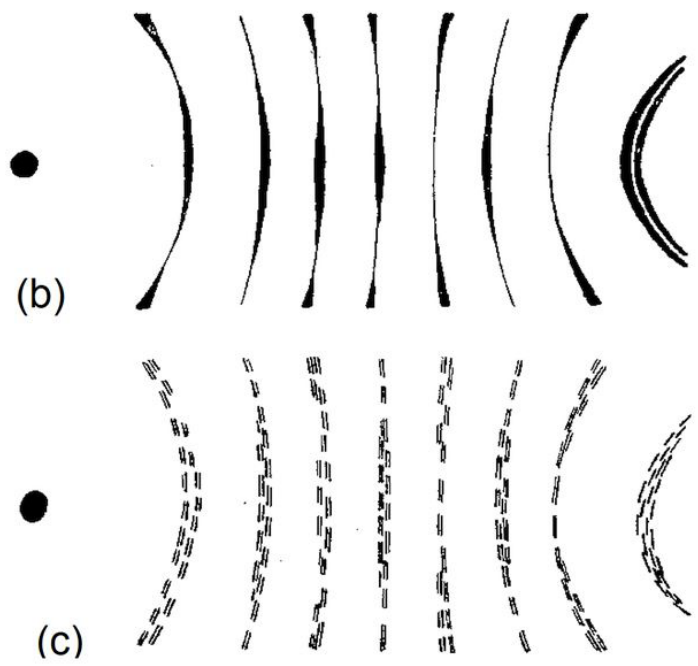

Figure 9 - Schematic powder diffraction diagrams of polycrystalline tungsten wire. (a) Initial state, fine-grained sample after plastic deformation. Broadened diffuse lines indicate the crystal lattice is distorted by internal stresses; (b) After partial annealing (such as $900^{\circ} \mathrm{C}$ for 10 minutes), (400) line peak splitting due to the recovery; c) Coarse-grained sample after recrystallisation $\left(\mathrm{T}>1800^{\circ} \mathrm{C}\right)^{77,78}$. the lattice curvature and the crystallite size upon the X-ray line broadening ${ }^{86,96,97}$. The X-ray line sharpening observed with increasing plastic deformation or partial annealing was also investigated and related to the recovery of the dislocation structure ${ }^{80,81,86,89,91,93}$. According to Wood $^{86}$ in 1939, the "crystalline condition of the cold-worked metal" was marked by two extremes: an unstable state, which shows an expanded lattice and diffuse X-ray line breadth; and a recovered state, which features a contracted lattice and sharper diffraction lines. In the case of pure copper, the continuous cold working caused the broadening of the diffraction lines, followed by the sharpening of these lines (see Figures 11a to 11d). The lattice also changed from an "expanded state" (diffuse diffraction lines, see Figure 11c) to a "contracted state" (sharp diffraction lines, see Figure 11d). According to the author ${ }^{86}$, the residual peak broadening of the recovered stated was due to the fine-grain effect (crystallite formation or grain fragmentation due to the plastic deformation). In 1954, Beck ${ }^{93}$ reasoned that all of the line broadenings might be "annealed out" by a recovery mechanism, provided that the recrystallisation did not start earlier (see Figures 12a and 12b). Van Arkel and Burgers ${ }^{81}$ found in 1928 considerable line sharpening due to recovery took place before the recrystallisation during the annealing of cold drawn wires of thoriated tungsten at temperatures below $1900 \mathrm{~K}$, suggesting that the presence of the thorium oxide particles delayed the onset of recrystallisation, and the recovery was more effective at higher annealing temperatures (see Figures 12c). Careful positioning of the single-crystal hexagonal metals during the tensile testing, according to Schmid's law ${ }^{76}$, allowed these test-pieces to be plastically deformed using one single active glide system (easy glide), and the majority of the work hardening could be recovered at room temperature without any sign of recrystallisation ${ }^{89,93}$. In 1915, Rosenhain had already identified the recovery of the mechanical properties of plastically deformed metals without any visible change in the deformed microstructure due to annealing ${ }^{46}$.

By mid-1950s, the basics of the recovery and recrystallisation were already well known ${ }^{93,94}$. The free energy of a crystalline metal was increased during the plastic deformation due to an

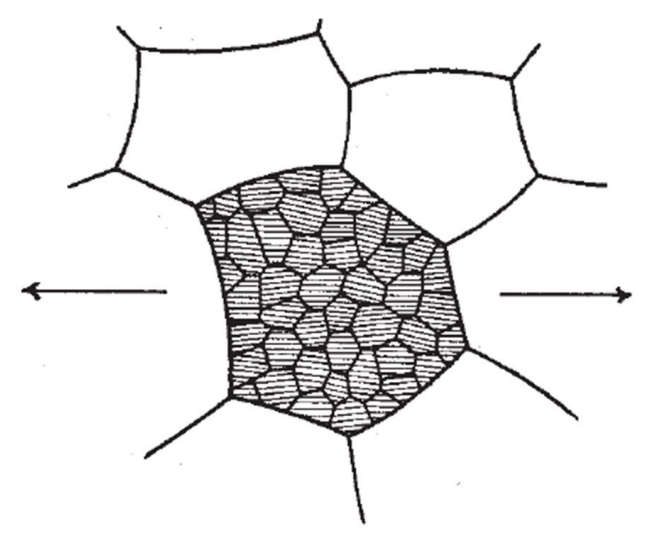

Figure 10 - Simplified scheme of the plastic deformation of a polycrystalline metal. The pattern inside a coarse grain represents the crystallites produced due to the plastic deformation. The orientations of the crystallites are represented by the hatching ${ }^{88}$. 

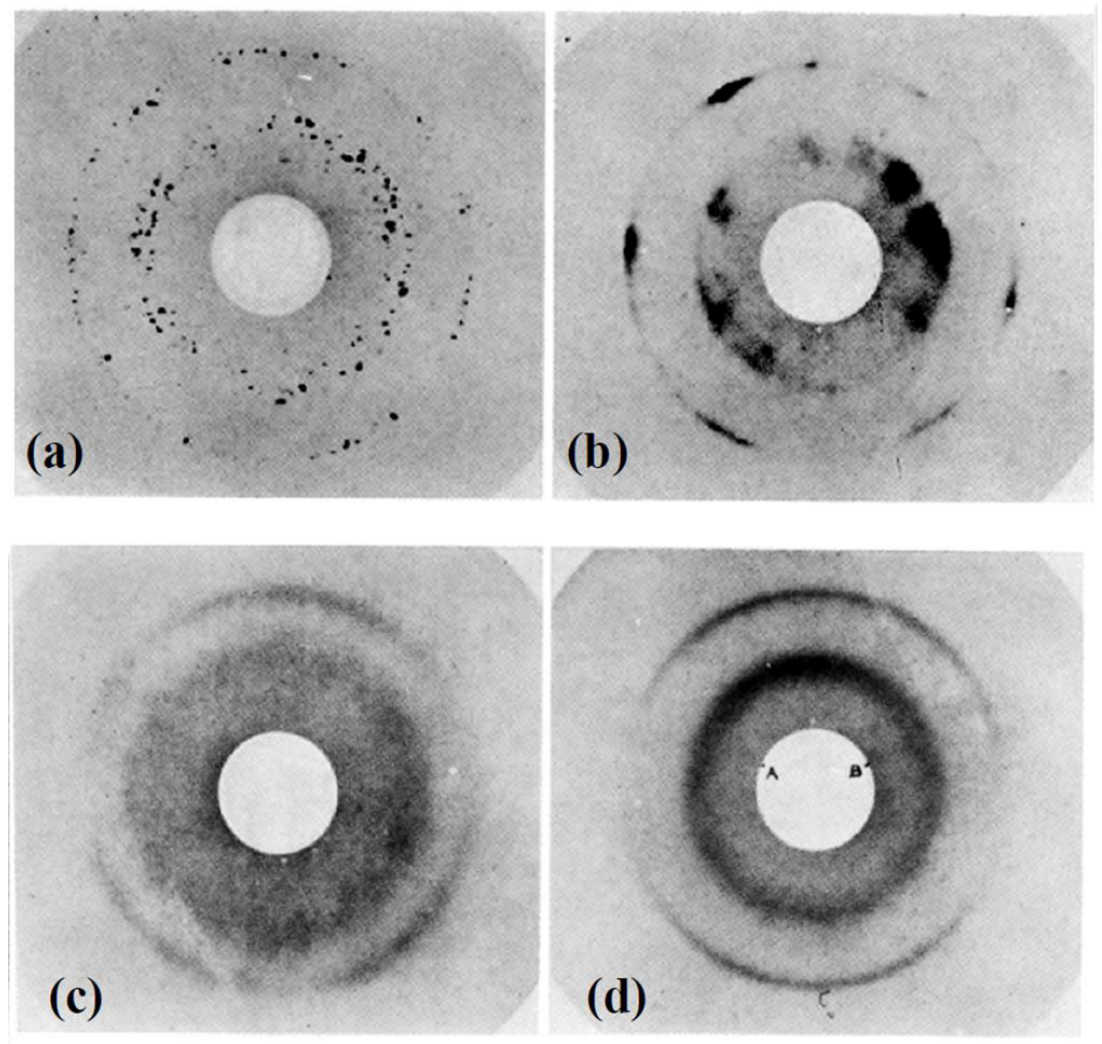

Figure 11 - Back-reflection spectrometry, pure copper. (a) Initial state, the annealed sample shows diffractions ring with separated sharp reflection spots, representing coarse grains $\left(10^{-1}\right.$ to $\left.10^{-2} \mathrm{~cm}\right)$; (b) Sample after $4 \%$ reduction shows a transition from diffraction rings to continuous arcs and onset of diffuse diffraction. The inner ring is a (400) doublet and the outer ring a (331) $\beta$; (c) Sample after $80 \%$ reduction shows more diffuse diffraction rings and an increase in diameter of the inner ring. The shift of the (400) ring indicates that the internal strain caused a lattice expansion $(\sim 0.13 \%)$; (d) The same sample after further $15 \%$ reduction in thickness. The radial diffusion of the rings decreased, indicating some recovery without recrystallisation ${ }^{86}$.
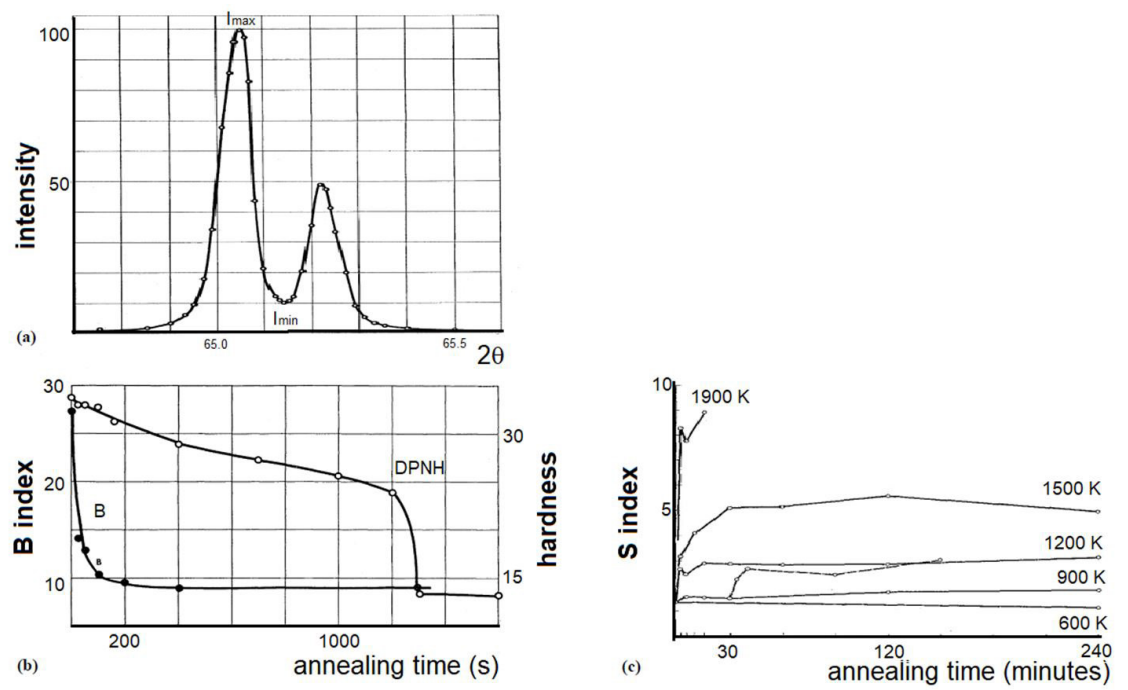

Figure 12 - (a) Diffracted X-ray intensity as a function of the Bragg angle for an Al single crystal after cold-working and annealing for 100 seconds at $350^{\circ} \mathrm{C},(220)$ plane reflection. Figure adapted from ${ }^{91}$; (b) Isothermal line sharpening of cold-rolled pure $\mathrm{Al}$ single crystals is finished after 200 seconds of annealing (see B index). The separation of the doublet was used as an index of line broadening (B index). The softening of the Al, measured by diamond pyramid hardness number (DPHN), is over after 1200 seconds of annealing. Most of the (200) line sharpening took place by a recovery process. Figure adapted from ${ }^{91}$; (c) Evolution of the doublet line sharpness index, $\mathrm{S}=\mathrm{I}_{\max } / \mathrm{I}_{\min }$, during the annealing of $\mathrm{W}$ wires alloyed with $1 \%$ of $\mathrm{ThO}_{2},(321)$ and (400) doublets. The increase in the sharpness of the lines during the annealing at temperatures below recrystallisation at $1900 \mathrm{~K}$ indicates the action of a recovery mechanism between 900 and $1500 \mathrm{~K}$. Figure adapted from ${ }^{81}$. 
increase in the area of interfaces and the density of dislocations, creating an unstable microstructure ${ }^{43}$. Less than $10 \%$ of the energy consumed in the plastic deformation was stored in the microstructure of the cold deformed metals ${ }^{93,94}$ and the kinetics to release this excess free energy was dependent on atomistic mechanisms. As the kinetics of this transition was sluggish at low homologous temperatures, the unstable microstructure could be retained after the plastic deformation. When this unstable microstructure was annealed, the thermally activated processes provided mechanisms to remove and reorganise the defects into lower energy configuration ${ }^{43,93,94}$. During the annealing, the deformed microstructure could be partially restored by recovery (annihilation and rearrangement of the dislocations without any interface migration) and recrystallisation (removal of the dislocation excess by interface migration $)^{43,93}$. The boundaries between the various annealing phenomena (recovery, recrystallisation and grain growth) were known to be usually blurred, but the recrystallisation could be formally described in terms of nucleation and growth stages ${ }^{43}$.

The plastic deformation of metals at low homologous temperature modifies the X-ray reflections due to changes in the crystal planes spacing; alterations in the character of the reflections; broadening of the Debye-Scherrer rings; loss of the alpha doublet resolution; modifications in the reflection's intensity; creation of preferred orientation of the crystallographic planes and directions with increasing plastic deformation; presence of arcs in the Debye-Scherrer patterns show; and formation of crystallites ${ }^{53,93,96,97}$. Between the 1920 s and 1950 s, the X-rays were practically the only means of studying the internal structure of metals to explain the nature of their plasticity ${ }^{53,90-101}$ and the first direct measurement of dislocation density via X-rays was finally published in 1953, indicating values of dislocations densities between $10^{7}$ and $10^{8}$ for annealed metallic samples and between $10^{9}$ and $10^{11}$ for cold-worked metallic samples ${ }^{99}$. These results were obtained by assuming that the dislocations in the crystallites were randomically arranged, meaning they were not organised as an array of dislocations. According to Gay et al. ${ }^{99}$, however, the existence of perfect regions of the crystal interconnected by distorted dislocation-rich volumes in the microstructure of the cold-worked metal was an indication of the heterogeneous dislocation distribution in the cold-hardened state, as the crystallites presented much lower dislocations density that these boundaries, see Figure $13 \mathrm{a}^{99,100}$

The mechanisms for the multiplication and the locking of the moving dislocations during the plastic deformation of metals were already known, and the resulting strain hardening was related to an increase in the number of dislocation locks ${ }^{100}$. In this sense, X-ray investigation of a single crystal of $\mathrm{Al}$ after the plastic deformation used the presence of deformation bands to explain the geometry of a magnified Laue streak ${ }^{79}$. X-ray results were also used to explain the grain misorientation caused by the heterogeneous distribution of dislocations in the as-deformed and recovered states ${ }^{100}$. According to the authors ${ }^{100}$, the presence of a background intensity between the spots along the Debye-Scherrer rings suggested a continuous change of curvature across a crystallite boundary. The boundary regions were plastically curved and

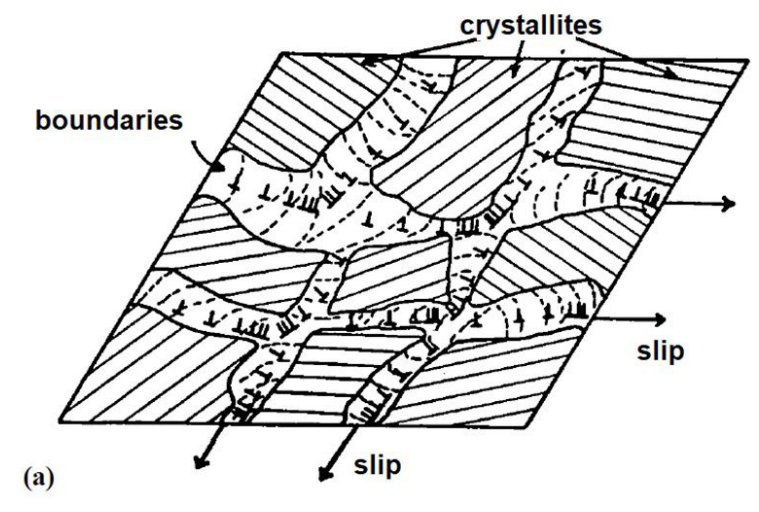

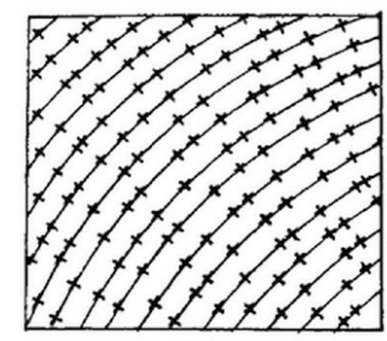

(b)

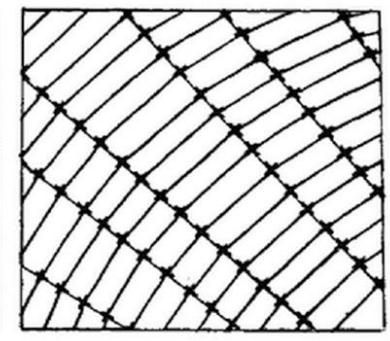

(c)

Figure 13 - (a) Schematic diagram of a plastically deformed grain with internal presence of dislocation-rich boundaries and dislocationpoor crystallites. The arrows indicate the slip directions. Figure adapted from ${ }^{100}$; (b) and (c) Nature of the polygonisation in a bent crystal lattice during recovery. The crosses represent the excess positive dislocations remaining on the glide-planes after bending; (b) As-bent crystal with homogenous distribution of the excess dislocations; (c) Annealed condition, showing the reorganisation of the excess dislocations by poligonisation ${ }^{102}$. 
contained large numbers of excess dislocations, attesting that the crystallites in the as-deformed state could not be produced by the mere fragmentation of a larger crystal ${ }^{100}$. The recovery was also associated with the rearrangement of the crystallite boundaries dislocations, such as poligonisation, to locally reduce the strain energy, see Figures $13 \mathrm{~b}$ and $13 \mathrm{c}^{101}$. Indeed, most of the understanding and conjecturing about the dislocation distribution and organisation in the cold-worked and annealed states were derived from X-ray diffraction experiments ${ }^{101,103}$, but soon new experimental techniques brought a better understanding about dislocations and plasticity, recovery and recrystallisation of metals.

\section{Final Comments}

The millenary experience acquired on work hardening, recrystallisation and grain growth began to be correlated with the knowledge coming from other areas, such as the plasticity, the thermodynamics of solutions and the dislocation theories. The evolution of the experimental techniques, such as transmission electron microscopy and selected area electron diffraction helped the development of the recrystallisation and the plasticity theory of metals ${ }^{104,105}$. In 1934, Orowan and Zur Kristallplastizität ${ }^{106}$, Taylor ${ }^{107}$ and Polanyi ${ }^{108}$ postulated the edge dislocation concept independently to explain the plastic deformation of metals by the plane slip along preferential crystallographic directions through the movement of a linear defect, which was associated to elastic energy of the lattice around this line. In 1939/40 Johannes Burgers introduced the concept of screw dislocation based on the seminal work of Volterra ${ }^{109}$ and defined the displacement vector, known as the Burges vector ${ }^{110,111}$. The dislocation theory gradually helped the understanding of work hardening, recovery and recrystallisation ${ }^{90-95}$.

In 1949, Robert W. Cahn ${ }^{112}$ published his classic work on the polygonisation and sub-grain formation during the annealing of single crystals plastically deformed by bending (see Figures $13 \mathrm{~b}$ and 13c). This work was an essential landmark as he, in a pioneering way, applied the theory of dislocations and presented experimental evidence of the dislocation re-arrangement during the annealing of the deformed crystalline materials. In 1949, Heidenreich ${ }^{113}$, working for the Bell Telephone Laboratories, observed for the first time the domain structure and the subgrain-structure in pure $\mathrm{Al}$ and $\mathrm{Al}-\mathrm{Cu}$ alloy using a transmission electron microscope - an electrolytic method for preparing TEM thin foils had to be developed and tested. The groundbreaking results (see Figures 14a to 14d) were indicated that cold work produced the fragmentation of deformed grains into crystallites

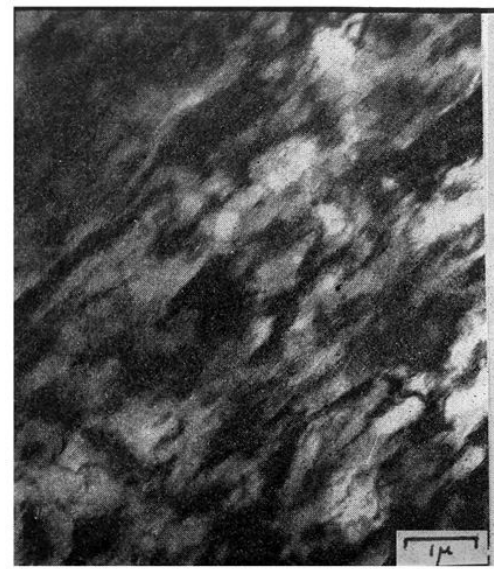

(a)

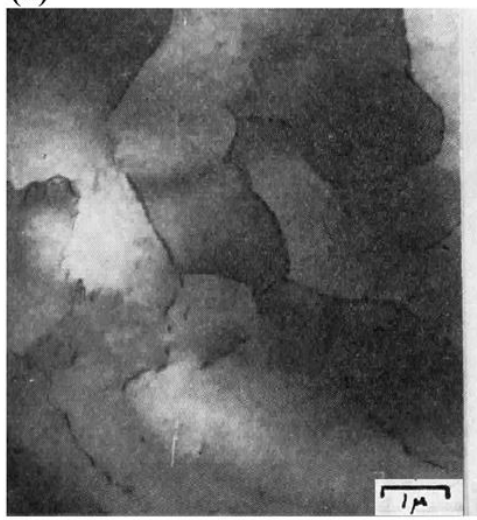

(c)

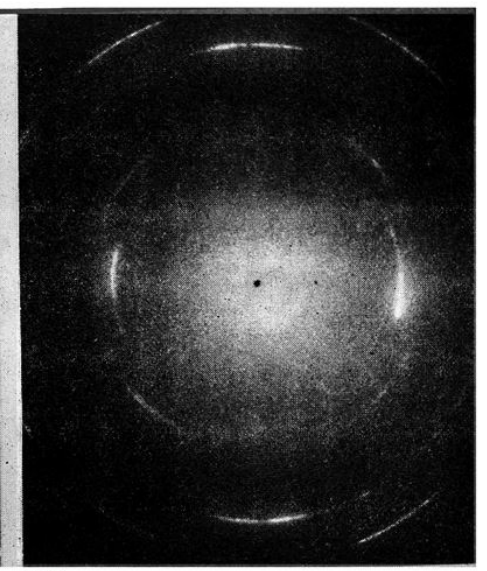

(b)

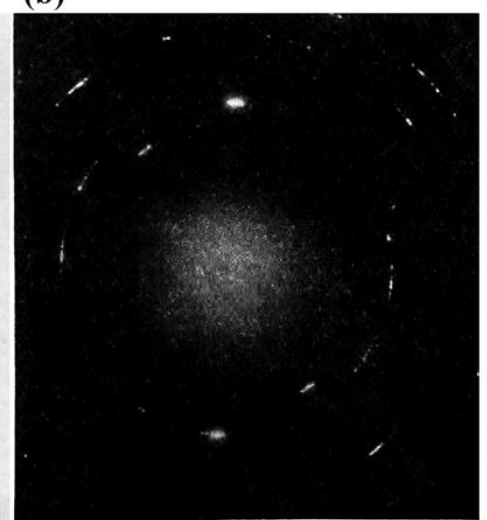

(d)

Figure 14 - (a) and (b) Transmission electron micrograph and electron diffraction pattern from a thin section of as-rolled Al-4Cu alloy. The preferred orientation is evident in the diffraction pattern, and the fragmentation caused by rolling is apparent in the micrograph. (c) and (d) Partially annealed sample of cold-worked pure aluminium showing a domain (crystallite) structure of $1 \mu \mathrm{m}$ diameter. Electron diffraction pattern showing variations in the orientation of the crystallites. Figures adapted from ${ }^{113}$. 


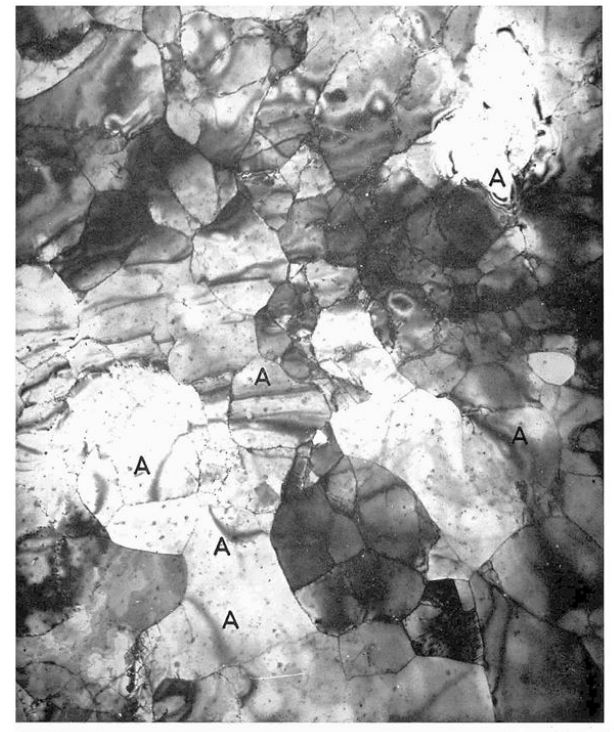

(a)

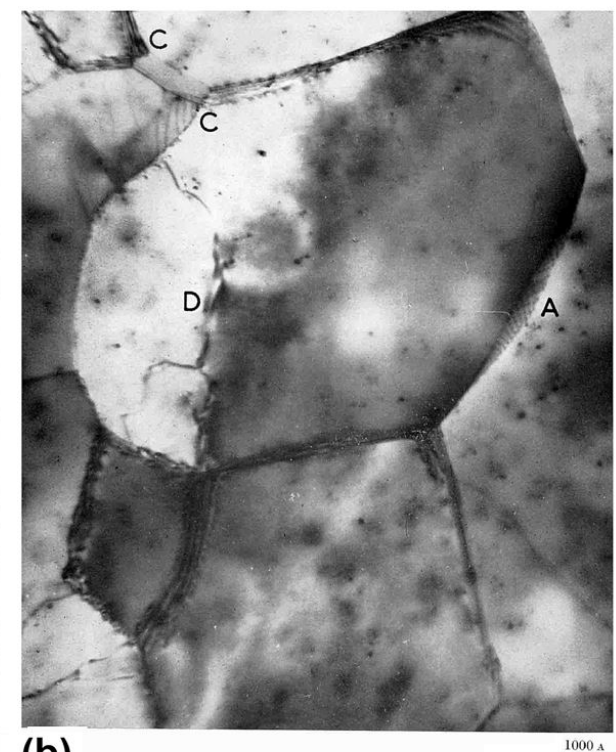

(b)

Figure 15 - Direct observations of the arrangement of the dislocations in aluminium after annealing at $350^{\circ} \mathrm{C}$. (a) Formation of crystallites of $\sim 1 \mu \mathrm{m}$ with angular misorientation of $1.5^{\circ}$ and dislocation density of $10^{10} \mathrm{~m}^{-2}$. Areas A represent extinction contours; (b) Detail of the sub-grain (crystallite) boundaries formed by dislocations network: points $\mathrm{C}$ : dislocation nodes; point $\mathrm{D}$ : isolated dislocations; point A: square cross-grid, and points $\mathrm{B}$ are other dislocation networks. Figures adapted from ${ }^{103}$.

of approximately $20 \mathrm{~nm}$ in size, which were inhomogeneously deformed and misoriented. According to the Heidenreich ${ }^{113}$, during the recovery of the cold-worked condition, nucleation and growth processes produced larger reoriented domains of 1 to $3 \mu \mathrm{m}$. The author also concluded that:

"Further work in improving the thinning technique to obtain larger usable areas of the (TEM) section is required. When this is done, work dealing with grain boundaries, slip, cold-work domains, and recrystallisation can be more effectively carried on to obtain new information. The necessary extension of the work to other metals and alloys is obvious."

In the late 1940s, the first models of "recrystallisation nucleation" 102,114 and strain-induced grain boundary migration ${ }^{115}$ were proposed. The available knowledge on plastic deformation, recovery and recrystallisation at the beginning of the 1950 s was well summarised by classical authors, such as Beck ${ }^{93}$, Titchener and Bever ${ }^{94}$ and Burke and Turnbull ${ }^{95}$. The validation of the vacancies diffusion mechanism consolidated the diffusion theory in metals and alloys in the atomic scale $\mathrm{e}^{116,117}$ and contributed to a better understanding of the recovery and recrystallisation mechanisms, such as the interaction between the solute in solid solution and the moving grain boundary ${ }^{118}$. The development of the fundamental of the recrystallization kinetics was performed nearly independently from the studies on the recrystallization mechanisms and around 1940 the global recrystallization kinetics (volume fraction recrystallized as a function of time for isothermal annealing) was already established, the Johnson-Mehl-Avrami-Kolmogorov followed the JMAK equation ${ }^{119-123}$. With the popularisation of the transmission electron microscopy and the consolidation of the dislocation theory, the deformation substructure and its evolution during annealing could be studied and understood with greater detail (see Figure 15a and 15b) ${ }^{103}$. Finally, at the beginning of the 1960 s, Swan ${ }^{124}$ studied in detail the dislocation arrangements in face-centred cubic metals and alloys, while Keh and Weissmann ${ }^{125}$ did the same for the body-centred cubic metals and alloys, also using transmission electron microscopy.

Almost 140 years have passed since Kalischer first coined the term "Krystallisation" in $1881^{33,34}$ and a large volume of scientific and technological knowledge has been accumulated during this period. Although several scientific aspects of the recrystallisation still need further explanations ${ }^{126}$, the available expertise already allows a satisfactory control of the microstructure of the metallic materials during its thermomechanical processing.

\section{Acknowledgements}

The authors would like to thank the support of the librarians of the Department of Metallurgical and Materials Engineering, Polytechnic School, University of São Paulo. Additionally, Prof. Cesar R. F. Azevedo would like to thank Prof. T. Cescon, Prof. I. G. S. Falleiros and Prof. F. J. G. Landgraf for the encouragement, Dr A. Feller for the discussions, and the Brazilian National Council for Scientific and Technological Development $(\mathrm{CNPq})$ for the research grant (Process: 302077/2016-2).

\section{References}

1. Tylecote RF. A history of metallurgy. London: The Metals Society; 1976.

2. Wertime TA. The Begginings of metallurgy: a new look. Arguments over diffusion and independent inventions ignore the complex 
metallurgic crafts leading to iron. Science. 1973;182(4115):87587. http://dx.doi.org/10.1126/science.182.4115.875.

3. Patterson CC. Native copper, silver, and gold accessible to early metallurgists. Am Antiq. 1971;36(3):286-321. http://dx.doi. org/10.2307/277716.

4. Smith CS. A search for structure: selected essays on science, art and history. Cambridge: The MIT Press; 1983.

5. Schroeder DL, Ruhl KC. Metallurgical characteristic of North American prehistoric copper work. Am Antiq. 1968;33(2):1629. http://dx.doi.org/10.2307/278518.

6. Aldenderfer M, Craig NM, Speakman RJ, Popelka-Filcoff P. Four-thousand-year-old gold artifacts from the Lake Titicaca basin, southern Peru. Proc Natl Acad Sci USA. 2008;105(13):5002-5. http://dx.doi.org/10.1073/pnas.0710937105. PMid:18378903.

7. Zori C. Extracting insights from prehistoric andean metallurgy: political organization, interregional connections, and ritual meanings. J Archaeol Res. 2019;27(4):501-56. http://dx.doi. org/10.1007/s10814-019-09128-7.

8. Cortés LL, Scattolin MC. Ancient metalworking in South America: a 3000-year-old copper mask from the Argentinian Andes. Antiquity. 2017;91(357):688-700. http://dx.doi. org/10.15184/aqy.2017.28.

9. Vatican Museums. The Metropolitan Museum of Art. The Vatican collections: the Papacy and art [Internet]. New York: The Metropolitan Museum of Art; 1982 [cited 2007 Jan 5]. Available from: https:// archive.org/details/TheVaticanCollectionsThePapacyandArt

10. Hartmann C, Hammerl F, Volk W. Experimental analysis of Roman coin minting. Journal of Archaeological Science: Reports. 2019;25:498-506. http://dx.doi.org/10.1016/j.jasrep.2019.05.007.

11. Fajfar H, Rupnik Ž, Šmit Z. Analysis of metals with luster: roman brass and silver. Nucl Instrum Methods Phys Res B. 2015;362:194-201. http://dx.doi.org/10.1016/j.nimb.2015.09.081.

12. Calliari I, Magrini M, Martini R, Tellini C, Pava EV. Metallurgical and technological investigation on augustean auxiliary coins from Thraco-Moesia. ArcheoSciences. 2011;35(35):9-18. http:// dx.doi.org/10.4000/archeosciences. 2879.

13. Scott DA. Metallography and microstructure of ancient and historic metals [Internet]. Marina del Rey, CA: Getty Conservation Institute, Archetype Books; 1991 [cited 2007 Jan 5]. Available from: http://www.getty.edu/conservation/publications_resources/ pdf_publications/pdf/metallography.pdf

14. Comelli D, D’orazio M, Folco L, El-Halwagy M, Frizzi T, Alberti R, et al. The meteoritic origin of Tutankhamun's iron dagger blade. Meteorit Planet Sci. 2016;51(7):1301-9. http:// dx.doi.org/10.1111/maps.12664.

15. Muhly JD, Maddin R, Stech T, Özgen E. Iron in anatolia and the nature of the hittite iron industry. Anatolian Studies. 1985;35:67-84. http://dx.doi.org/10.2307/3642872.

16. Pense AW. Iron through the ages. Mater Charact. 2000;45(45):353-63. http://dx.doi.org/10.1016/S1044-5803(00)00105-4.

17. Hosford WF. Elementary materials science. Materials Park: AMS International; 2013.

18. Fulford M, Sim D, Doig A, Painter J. In defence of Rome: a metallographic investigation of Roman ferrous armour from Northern Britain. J Archaeol Sci. 2005;32(2):241-50. http:// dx.doi.org/10.1016/j.jas.2004.09.003.

19. Biringuccio V. The pirotechnia of Vannoccio Biringuccio: the classic sixteenth-century treatise on metals and metallurgy. In: Smith CS, Gnudi MT, editors.The art of the goldsmith. New York: over Publications; 2013. p. 363-368.

20. Sisco AG, Smith CS. Ercker's treatise on ores and assaying. Chicago: University of Chicago Press; 1951.

21. Sisco AG, Smith CS. Réamur's memoirs on steel and iron. Chicago: University of Chicago Press; 1956.

22. Smith CS. History of metallography: the development of ideas on the structure of metals before 1890. Chicago: University of Chicago Press; 1960.
23. Vander Voort GF, Smith CS, Ritchie RO, Laird C, Gurland J, Kiepura RT. History of fractography. In: ASM International. ASM handbook: fractography. 9th ed. Materials Park: ASM; 1987.

24. Hull D. Fractography: observing, measuring and interpreting fracture surface topography. Cambridge: Cambridge University Press; 1999.

25. Lynch SP, Moutsos S. A brief history of fractography. In: Gdoutos EE, editor. Fracture of nano and engineering materials and structures. Dordrecht: Springer; 2006. http://dx.doi. org/10.1007/1-4020-4972-2 318.

26. Great Britain. Report of the Commissioners appointed to inquire into the application of iron to railway structures [Internet]. Great Britain: William Clowes and Sons, For her Majesty's Stationary Office; 1849 [cited 2007 Jan 5]. Available from: https://babel. hathitrust.org/cgi/pt?id=nnc1.cu09922130\&view $=1$ up\&seq $=8$

27. Kirkaldy D. Results of an experimental inquiry into the tensile strength and other properties of various kinds of wrought iron and steel [Internet]. London; 1862 [cited 2007 Jan 5]. Available from: https://archive.org/details/resultsanexperi00kirkgoog/ page $/ \mathrm{n} 8$

28. Chernoff D. The manufacture of steel and mode of working it. J Franklin Inst. 1876;102(3):177-86. http://dx.doi.org/10.1016/00160032(76)90233-7.

29. Sadovsky VD. Tschernoff and the development of the theory of heat treatment of steel. In: Smith CS, editor. The sorby centennial symposium on the history of metallurgy. New York: Gordon and Breach; 1965. p. 189-208.

30. Percy J. Metallurgy iron and steel [Internet]. London: John Murray, Albemarle Street; 1864 [cited 2007 Jan 5]. Available from: https://archive.org/details/bub_gb_RYpBAAAAIAAJ

31. Savart F. Recherches sur la structure des metáux. Ann Chim Phys. 1829;41:61.

32. Noguès AF. Influence des hautes températures sur l'état moléculaire de certains corps. Compt. Rend. Acad. 1858;47:832.

33. Kalischer S. Ueber den Einfluss der Wärme auf die Molekularstruktur des Zinks. Berichte d. Deut. chem. Gesellschaft. 1881;16:2727 53. http://dx.doi.org/10.1002/cber.188101402245.

34. Kalischer S. Ueber die Molekularstruktur der Metalle. Ber Dtsch Chem Ges. 1882;15(1):702-12. http://dx.doi.org/10.1002/ cber. 188201501160 .

35. Sorby HC. The application of very high powers to the study of the microscopical structure of steel. J Iron Steel Inst. 1886;30(1):140-5.

36. Sorby HC. On the microscopical structure of iron and steel. J Iron Steel Inst. 1887;31(1):255-88.

37. Sorby HC. On the microscopical structure of iron and steel: meeting of the iron and Steel Institute (1885). In: Smith CS, editor. A history of metallography: the development of ideas on the structure of metals before 1890. Chicago: University of Chicago Press; 1960.

38. Hadfield R. The great work of sorby. J Microsc. 1920;40(4):114 8. http://dx.doi.org/10.1111/j.1365-2818.1920.tb06122.x.

39. Humphreys DW. Sorby: the father of microscopical petrography. In: Smith CS, editor. The sorby centennial symposium on the history of metallurgy. New York: Gordon and Breach; 1964. p. 17-42.

40. Aust KT. Kalischer and Recrystallization in the Nineteenth Century. Metall Trans. 1970;1(7):2055-65. http://dx.doi. org/10.1007/BF02642827.

41. Stead JE. The crystalline structure of iron and steel. Iron and Steel Inst. 1898;53(1):145-205.

42. Stead JE. Brittleness produced in soft steel by annealing. J Am Soc Nav Eng. 1898;10(4):965-81. http://dx.doi. org/10.1111/j.1559-3584.1898.tb01919.x.

43. Humphreys FJ, Hatherly M. Introduction. In: Humphreys FJ, editor. Recrystallization and related annealing phenomena. 2nd ed.Amsterdam: Elsevier; 2004. Chapter I, p. 1-10. 
44. Ewing JA, Rosenhain W. Bakerian lecture, the crystalline structure of metals. Philos Trans A Math Phys Eng Sci [Internet]. 1900 [cited 2007 Jan 5];193:353-72. Available from: https:// royalsocietypublishing.org/doi/pdf/10.1098/rsta.1900.0011

45. Ewing JA, Rosenhain W. The crystalline structure of metals, second paper. Philos Trans A Math Phys Eng Sci [Internet]. 1900 [cited 2007 Jan 5];195:262-73. Available from: https:// royalsocietypublishing.org/doi/pdf/10.1098/rsta.1900.0029

46. Rosenhain W. Metallurgy: An introduction to the study of physical metallurgy [Internet]. New York: D. Van Nostrand Company; 1915 [cited 2007 Jan 5]. Available from: https:// archive.org/details/cu31924004699082

47. Carpenter $\mathrm{HCH}$, Elam CF. Crystal growth and recrystallization in metals. J Inst Met. 1920;24:83-131.

48. Rosenhain W, Desch CH, Hatfield WH, Thompson FC, Bingham KE, Johnson F, et al. Discussion on Carpenter and Elam's Paper. J Inst Met. 1920;24:131-48.

49. Haüy A. Traité de Cristallography, suivi d'une application des principes de cette science a la détermination des espèces minérales et d'une nouvelle méthode pour mettre les formes cristallines en projection [Internet]. Paris: Bachelier et Huzard; 1822. vol. 2 [cited 2007 Jan 5]. Available from: https://archive. org/stream/traitdecristal02ha\#page/n6/mode/2up

50. Miller WH. A treatise on crystallography [Internet]. Cambridge: J. and J. J. Deighton; 1839 [cited 2007 Jan 5]. Available from: https://archive.org/details/treatiseoncrysta00millrich

51. Friedrich W, Knipping P, Laue M. Interferenzerscheinungen bei Röntgenstrahlen. Ann Phys. 1913;346(10):971-88. http:// dx.doi.org/10.1002/andp.19133461004.

52. Thomas JM. The birth of X-ray crystallography. Nature. 2012;491(7423):186-7. http://dx.doi.org/10.1038/491186a. PMid:23135450

53. Authier A. Early days of X-ray crystallography. Oxford: Oxford University Press; 2013. http://dx.doi.org/10.1093/ acprof:oso/9780199659845.001.0001.

54. Bragg WL. The diffraction of short electromagnetic waves by a crystal. Proc Camb Philos Soc [Internet] . 1913 [cited 2007 Jan 5];17:43-57. Available from: https:/archive.org/details/ proceedingsofcam $1718191316 \mathrm{camb} /$ page/n59

55. Bragg WL. The structure of some crystals as indicated by their diffraction of X-rays. Proc R Soc Lond, A Contain Pap Math Phys Character. 1913;89(610):248-77. http://dx.doi.org/10.1098/ rspa.1913.0083.

56. Bragg WH, Bragg WL. The structure of the diamond. Proc. Roy. Soc. A. 1913;89(610):277-91. http://doi.org/10.1098/ rspa.1913.0084.

57. Bragg WH, Bragg WL. X rays and crystal structure [Internet] London: G. Bell and Sons; 1915 [cited 2007 Jan 5]. Available from: https://archive.org/details/xrayscrystalstru00braguoft

58. Ewald PP. Fifty years of X-ray diffraction. Utrecht: International Union of Crystallography; 1962.

59. Ewald PP. William Henry Bragg and the new crystallography. Nature. 1962;195(4839):320-5. http://dx.doi.org/10.1038/195320a0.

60. Owen EA, Blake GG. X-rays and metallic crystals. Nature. 1914;92(2312):686-7. http://dx.doi.org/10.1038/092686b0

61. Moseley HGJ, Darwin CG. The reflexion of the X-rays. Lond Edinb Dublin Philos Mag J Sci. 1913;26(151):210-32. http:// dx.doi.org/10.1080/14786441308634968.

62. Moseley HGJ. The high-frequency spectra of the elements. Philosophical Magazine Series 6. 1913;26(156):1024-34. http:// dx.doi.org/10.1080/14786441308635052.

63. Moseley HGJ. The high-frequency spectra of the elements. Part II. Philosophical Magazine Series 6. 1914;27(160):703-13. http://dx.doi.org/10.1080/14786440408635141.

64. Bragg WJ. The crystalline structure of copper. Phil. Mag. Series. 1914;28(165):355-60. http://dx.doi.org/10.1080/14786440908635219.
65. Westgren A, Phragmén G. X-ray analysis of copper-zinc, silverzinc, and gold-zinc alloys. Philosophical Magazine Series 6. 1925;50(295):311-41. http://dx.doi.org/10.1080/14786442508634742.

66. Westgren A, Phragmén G. X-ray studies on alloys. Trans Faraday Soc. 1929;25(0):379-85. http://dx.doi.org/10.1039/ TF9292500379.

67. Bragg L. Recent advances in the study of the crystalline state. Science. 1948;108(2809):455-63. http://dx.doi.org/10.1126/ science.108.2809.455. PMid:17733828

68. Guinier A. Technische Anwendung der Rontgenanalyse: metallurgie. Z Kristallogr. 1964;120:125-36. http://dx.doi. org/10.1524/zkri.1964.120.16.125.

69. Kasper JS. Metal structures. Z Kristallogr. 1964;120:53-70. http://dx.doi.org/10.1524/zkri.1964.120.16.53.

70. Paxton HW, Austin JB. Historical account of the contributions of E. C. Bain. Metall Trans, B, Process Metall. 1972;3:1035-42. http://dx.doi.org/10.1007/BF02642435.

71. Hardouin Duparc OBM. The Preston of the Guinier-Preston Zones: Guinier. Metall Mater Trans, A Phys Metall Mater Sci. 2010;41(8):1873-82. http://dx.doi.org/10.1007/s11661-0100320-5.

72. Keene HB. On the transmission of X-rays through metals. Nature. 1913;91(2285):607. http://dx.doi.org/10.1038/091607b0.

73. Mark H, Polanyi M, Schmid E. Vorgänge bei der Dehnung von Zinkkristallen. I. Z Phys. 1923;12(1):58-77. http://dx.doi. org/10.1007/BF01328082.

74. Mark H, Polanyi M, Schmid E. Vorgänge bei der Dehnung von Zinkkristallen. II. Z Phys. 1923;12(1):78-110. http://dx.doi. org/10.1007/BF01328083.

75. Mark H, Polanyi M, Schmid E. Vorgänge bei der Dehnung von Zinkkristallen. III. Z Phys. 1923;12(1):111-6. http://dx.doi. org/10.1007/BF01328084.

76. Schmid E, Boas W. Plasticity of crystals with special reference to metals. London: F. A. Hughes \& Co. Limited; 1950

77. Arkel AEV. Over de deformatie van het kristalrooster van metalen door mechanische bewerking. Physica. 1925;5:208-12.

78. Becker K. Der röntgenographische Nachweis von Kornwachstum und Vergütung in Wolframdrähten mittels des Debye-ScherrerVerfahrens. Z Phys. 1927;42(2-3):226-45. http://dx.doi. org/10.1007/BF01397131.

79. Gay P, Honeycombe RWK. X-ray asterisms from deformed crystals. Proc Phys Soc A. 1951;64(9):844-5. http://dx.doi. org/10.1088/0370-1298/64/9/111.

80. Dehlinger U. Uber die Verbreiterung der Debye-linien bei Kaltbearbeiteten Metallen. Z Kristallogr. 1927;65:615-31. http://dx.doi.org/10.1524/zkri.1927.65.1.615.

81. Arkel AEV, Burgers WG. Verbreiterung der Debye-Seherrerschen Linien von kaltbearbeitetem Wolframdraht und Wolframband als Funktion der Gluhtemperatur und Gluhdauer. Z Phys. 1928;48(9-10):690-702. http://dx.doi.org/10.1007/BF01339315.

82. Orowan E, Pascoe KJ. An X-ray criterion for distinguishing between lattice curvature and fragmentation. Nature. 1941;148(3755):467-8. http://dx.doi.org/10.1038/148467a0.

83. Wood WA. The effect of lattice distortion and fine grain on the X-ray spectra of metals. Lond Edinb Dublin Philos Mag J Sci. 1933;15(99):553-62. http://dx.doi.org/10.1080/14786443309462205.

84. Collins JA, Mathewson CH. Plastic deformation and recrystallization of aluminum single crystals. Trans Am Inst Min Metall Eng [Internet]. 1940 [cited 2007 Jan 5];137:150-67. Available from: http://www.aimehq.org/doclibrary-assets/books/ AIME\%20Technical\%20Publications \%20-\%201940\%20-\%20 A-E/AIME $\% 20$ Technical\%20Publications $\% 20-\% 201940 \% 20$ -\%20A-E\%20-\%20063.pdf

85. Paterson S, Orowan E. X-ray line broadening in coldworked metals. Nature. 1948;162(4130):991-2. http://dx.doi. org/10.1038/162991a0.

86. Wood WA. The lower limiting crystallite size and internal strains in some cold-worked metals. Proc R Soc Lond A Math 
Phys Sci. 1939;172(949):231-41. http://dx.doi.org/10.1098/ rspa.1939.0101.

87. Gough HJ, Wood WA. The crystalline structure of steel at fracture. Proc R Soc Lond A Math Phys Sci. 1938;165(922):358-71. http://dx.doi.org/10.1098/rspa.1938.0065.

88. Bragg WL. Theory of the strength of metals. Nature. 1942;149(3784):511-3. http://dx.doi.org/10.1038/149511a0.

89. Polanyi M, Scbmid E. Verfestigung und Entfestigung von Sn-Kristallen. Z Phys. 1925;32(1):684-712. http://dx.doi. org/10.1007/BF01331707.

90. Honeycombe RWK. Inhomogeneities in the plastic deformation of metal crystals. J Inst Met. 1951;80:45-56.

91. Lutts AH, Beck PA. Annealing of a cold rolled aluminum single crystal. J Met. 1954;6(2):257-60. http://dx.doi.org/10.1007/ BF03398008.

92. Mehl RF. A brief history of the science of metals. New York: American Institute of Mining and Metallurgical Engineers; 1948.

93. Beck PA. Annealing of cold worked metals. Adv Phys. 1954;3(11):245-324. http://dx.doi.org/10.1080/00018735400101203.

94. Titchener AL, Bever MB. The stored energy of cold work. Prog Met Phys. 1958;7:247-338. http://dx.doi.org/10.1016/05028205(58)90006-6.

95. Burke JE, Turnbull D. Recrystallization and grain growth. Prog Met Phys. 1952;3:220-92. http://dx.doi.org/10.1016/05028205(52)90009-9.

96. Warren BE, Averbach BL. The effect of cold-work distortion on X-ray patterns. J Appl Phys. 1950;21(6):595-9. http://dx.doi. org/10.1063/1.1699713.

97. Warren BE, Averbach BL. The separation of cold-work distortion and particle size broadening in X-ray patterns. J Appl Phys. 1952;23(4):497. http://dx.doi.org/10.1063/1.1702234.

98. Kelly A. Lawrence Bragg's interest in the deformation of metals and 1950-1953 in the Cavendish - a worm's-eye view. Acta Crystallogr A. 2013;69(1):16-24. http://dx.doi.org/10.1107/ S0108767312034356. PMid:23250056.

99. Gay P, Hirsch PB, Kelly A. The estimation of dislocation densities in metals from X-ray data. Acta Metall. 1953;1(3):315-9. http:// dx.doi.org/10.1016/0001-6160(53)90106-0.

100.Gay P, Hirsch PB, Kelly A. X-ray studies of polycrystalline metals deformed by rolling. III. The physical interpretation of the experimental results. Acta Crystallogr. 1954;7(1):41-9. http://dx.doi.org/10.1107/S0365110X54000060.

101.Hirsch PB. Mosaic structure. Prog Met Phys. 1956;6:236-339. http://dx.doi.org/10.1016/0502-8205(56)90008-9.

102.Cahn RW. A new theory of recrystallization nuclei. Proc Phys Soc A. 1950;63(4):323-36. http://dx.doi.org/10.1088/0370$1298 / 63 / 4 / 302$.

103.Hirsch PB, Horne RW, Whelan MJ. LXVIII. Direct observations of the arrangement and motion of dislocations in aluminium. Philos Mag. 1956;1(7):677-84. http://dx.doi. org/10.1080/14786435608244003.

104.Beck PA. Early history of the understanding of recrystallization in metal. In: Smith CS, editor. The sorby centennial symposium on the history of metallurgy. New York: Gordon and Breach; 1964. p. 313-331.

105.Okada K. History of plasticity and metal forming analysis. J Mater Process Technol. 2010;210(11):1436-54. http://dx.doi. org/10.1016/j.jmatprotec.2010.04.001.
106.Orowan E, Zur Kristallplastizität III. Über den mechanismus des Gleitvorganges. Z Phys. 1934;89:634-59. http://dx.doi. org/10.1007/BF01341480.

107. Taylor GI. The mechanism of plastic deformation of crystals. Part I.-Theoretical. Proc R Soc Lond A. 1934;145:312-87. http://dx.doi.org/10.1098/rspa.1934.0106.

108.Polanyi M. Über eine Art Gitterstörung die einen Kristall plastich machen könnte. Z Phys. 1934;89(9-10):660-4. http:// dx.doi.org/10.1007/BF01341481.

109. Volterra V. Sur l'equilibre des corps elastiques multiplement connexes. Ann Sci Ec Norm Super. 1907;24(3):401-517.

110. Burgers JM. Physics: some considerations on the fields of stress connected with dislocations in a regular crystal lattice. In: Nieuwstadt FTM, Steketee JA, editors. Selected papers of J. M. Burgers. Dordrecht: Springer; 1995. p. 335-389.

111. Burgers JM. Geometrical considerations concerning the structural irregularities to be assumed in a crystal. Proc Phys Soc Lond. 1940;52:2333. http://dx.doi.org/10.1088/0959-5309/52/1/304.

112. Cahn RW. Recrystallization of single crystals after plastic bending. J Inst Met. 1949;76:121-43.

113. Heidenreich RD. Electron microscope and diffraction study of metal crystal textures by means of thin sections. J Appl Phys. 1949;20(10):993-1010. http://dx.doi.org/10.1063/1.1698264.

114.Beck PA. The formation of recrystallization nuclei. J Appl Phys. 1949;20(6):633-4. http://dx.doi.org/10.1063/1.1698446.

115.Beck PA, Sperry PR. Strain induced boundary migration in high purity aluminum. J Appl Phys. 1950;21(2):150-2. http:// dx.doi.org/10.1063/1.1699614.

116. Smigelskas AD, Kirkendall EO. Zinc diffusion in alpha brass. Trans. AIME. 1947;171:130-42.

117. Seitz F. On the theory of diffusion in metals. Acta Crystallogr. 1950;3(5):355-63. http://dx.doi.org/10.1107/S0365110X50000999.

118. Lücke K, Detert K. A quantitative theory of grain boundary motion and recrystallization in metals in the presence of impurities. Acta Metall. 1957;5(11):628-37. http://dx.doi. org/10.1016/0001-6160(57)90109-8.

119. Kolmogorov AN. A statistical theory for the recrystallisation of metals. Izv. Akademii Nauk SSSR - Ser. Matemat in Russian. 1937;3:355-9.

120. Johnson WA, Mehl RF. Reaction kinetics in processes of nucleation and growth. Trans Metall Soc AIME. 1939;135:416-41.

121.Avrami M. Kinetics of phase change I. J Chem Phys. 1939;7(12):1103-12. http://dx.doi.org/10.1063/1.1750380.

122.Avrami M. Kinetics of phase change II. J Chem Phys. 1940;8(2):212-24. http://dx.doi.org/10.1063/1.1750631.

123.Avrami M. Kinetics of phase change III. J Chem Phys. 1941;9(2):177-84. http://dx.doi.org/10.1063/1.1750872.

124. Swan PR. Dislocations arrangements in face-centered cubic metals. In: Thomas G, Washburn J, editors. Electron microscopy and strength of crystals. New York: Interscience; 1963. p. 131-81.

125.Keh AS, Weissman S. Deformation structure in body-centered cubic metals. In: Thomas G, Washburn J, editors. Electron microscopy and strength of crystals. New York: Interscience; 1963. p. 231-300.

126.Rios PR, Siciliano F Jr, Sandim HRZ, Plaut RL, Padilha AF. Nucleation and growth during recrystallization. Mater Res. 2005;8(3):225-38. http://dx.doi.org/10.1590/S151614392005000300002 . 